Fanum

Sociológico

\section{Forum Sociológico}

Série II

$25 \mid 2014$

Número 25

\title{
Uma abertura para a cidade. Análise de uma reforma sócio-urbanística no bairro da Mouraria
}

\section{Giacomo Ferro}

\section{(2) OpenEdition}

12 Journals

\section{Edição electrónica}

URL: https://journals.openedition.org/sociologico/906

DOI: 10.4000/sociologico.906

ISSN: 2182-7427

\section{Editora}

CICS.NOVA - Centro Interdisciplinar de Ciências Sociais da Universidade Nova de Lisboa

\section{Edição impressa}

Paginação: 53-61

ISSN: 0872-8380

\section{Refêrencia eletrónica}

Giacomo Ferro, «Uma abertura para a cidade. Análise de uma reforma sócio-urbanística no bairro da Mouraria», Forum Sociológico [Online], 25 | 2014, posto online no dia 10 novembro 2014, consultado o 29 março 2022. URL: http://journals.openedition.org/sociologico/906 ; DOI: https://doi.org/10.4000/ sociologico.906

Este documento foi criado de forma automática no dia 29 março 2022.

(c) CICS.NOVA 


\title{
Uma abertura para a cidade. Análise de uma reforma sócio-urbanística no bairro da Mouraria
}

\author{
Giacomo Ferro
}

\section{Introdução}

1 Como pode mudar a ideia que nós temos de um bairro? Será devido às transformações da sua estrutura arquitetónica? Será a alternância de pessoas e dos grupos sociais que lá moram ou que o praticam no dia a dia? Ou dependerá talvez de uma mudança nas representações e significados que lhe são atribuídos pelas instituições que desempenham a tarefa de o governar, controlar e valorizar?

O bairro não é uma entidade isolada e imutável mas participa das transformações gerais que envolvem a cidade (Ledrut, 1978) e experimenta diferentes eixos de mudança que implicam processos complexos, articulados com a vasta variedade de elementos e factores contextuais que compõem as suas dinâmicas (Hannerz, 1980). No plano das políticas urbanas dos últimos vinte anos, importantes programas de requalificação e luta contra a exclusão social promovidos em contexto comunitário ou, mais especificamente, o desenvolvimento de conceções participativas de planeamento e intervenção, têm chamado atenção para a ideia de que o bairro é um terreno de ação e atenção central, no qual se ativam sinergias nos assuntos sociais, económicos e ambientais (Paquot, 2009; Galster, 2001; Smith, 2002; Savage et al., 2005).

3 Entre o outono de 2011 e o verão de 2012, o bairro da Mouraria, situado no centro de Lisboa, e os seus arredores foram envolvidos numa ação radical de intervenção a nível urbanístico que pretendia requalificar o tecido arquitetónico e reorganizar o cenário económico e social do seu território. A reforma agiu principalmente no espaço público, tendo em vista incutir novas práticas de utilização e apropriação através do fornecimento de novos equipamentos, da introdução de políticas securitárias e do envolvimento de novos atores sociais. Além disso, a reforma visa promover e veicular 
antigas e novas representações referidas ao lugar, incidindo na requalificação do seu património cultural (tão material, como imaterial) e na introdução de diferentes significados simbólicos e identitários.

4 o presente artigo quer apresentar um contributo para a análise da importante reforma sócio-urbanística implementada no bairro da Mouraria no curso deste recente passado. A partir de uma perspetiva crítica, este trabalho analisa os eixos de intervenção, as práticas políticas e as estratégias de atuação planeadas pelos agentes institucionais e associativos que a promoveram. Mais especificamente,dá-se particular atenção à descrição dos focos da reforma e das operações de produção de sentido que legitimaram as suas intervenções.

5 Parte integrante de um projeto de pesquisa sobre o impacto social das políticas urbanas de reforma em contexto de bairro, o trabalho é fruto de um estudo documental sobre os dois planos que estruturam a obra de reforma. Recorrendo à perspetiva etnografica, considerada não apenas um recurso metodológico, mas também uma forma de conhecimento, procurou-se documentar as fases de projeção e implementação da reforma conduzidas pelas entidades responsáveis (instituições e associações locais), e pelos diferentes atores sociais (moradores, trabalhadores, visitantes, empresários) envolvidos nas intervenções.

6 Na tentativa de responder à pergunta de partida: "como as políticas urbanas agem sobre a mudança social e as representações de um bairro?"; o estudo descreve as dinâmicas pelas quais, a partir das peculiaridades urbanas, históricas e sociais do bairro, o plano de reforma da Mouraria tenta implementar um processo de mudança social e económica no território. Ao mesmo tempo, este revela como tal processo de mudança social é suportado pela introdução e veiculação de imagens, conceitos e idealizações sobre o lugar que respondem a processos de "emblematização e estigmatização" (Menezes, 2012) do seu contexto socioespacial.

7 A análise da reforma e o trabalho de campo permitiram considerar a existência de diferentes visões e concetualizações que permearam a retórica projetual e as estratégias de atuação postas em prática pelos diferentes atores implicados no processo. Revelam-se assim maneiras e modelos de pensar o desenvolvimento territorial de forma diferente e às vezes conflitual. No entanto, no caso desta obra de reforma, estes tenderam a ser organizados e dirigidos face a um sentido de complementaridade, funcional e coerente com a construção de um renovado imaginário urbano. Por último, os dados recolhidos são, neste artigo, interpretados no sentido de individualizar as diretrizes das intervenções com o intuito de refletir sobre uma possível "hermenêutica da reforma": a qual parece encontrar a sua síntese no conceito, exógeno tanto quanto endógeno, de abertura.

\section{Entre segregação socioespacial e a construção de uma "tradição popular": história e representações de um bairro}

8 Como relata Marluci Menezes, a Mouraria pode ser considerada uma "invenção datada e instituída, através do foral do 1170" (Menezes, 2004: 81; 2012). Desde os primórdios da sua fundação, após a reconquista cristã de Lisboa, esta origem formal repercutiu-se, inclusive, nos elementos morfológicos da sua estrutura urbana que o caracterizavam 
como espaço segregado, assinado na altura, ao acolhimento e à contenção dos "mouros vencidos". O território, constringido fora das muralhas da cidade, tinha limites e fronteiras que o identificavam socioespacialmente face a uma condição de exclusão no que respeita à cidade. Mouraria representava então um território condicionado "do ponto de vista simbólico e urbano à elaboração de um complexo processo de estigmatização territorial" (Menezes, 2012: 72; 2004). Com o decorrer das circunstâncias sociais, históricas e económicas da cidade, a estrutura do bairro modificou-se, transbordando para lá dos antigos limites circunscritos pelo "gueto" e extendendo-se pelas zonas limítrofes. No entanto, o bairro continuaria marginalizado fora das muralhas da cidade. De facto, a história urbana e social da Mouraria mostra como essa foi inventada e posicionada "de forma a estar depois, ou a seguir a algum outro elemento ou referencial com mais representatividade urbana: nas traseiras do castelo de São Jorge, por detrás da zona ribeirinha, atrás da Baixa, etc." (Menezes, 2005: 34).

o bairro sempre se caracterizou pela sua pobreza e precariedade habitacional, atraindo, ao longo da sua história, sobretudo segmentos da população com dificuldades socioeconómicas. Os vários fluxos migratórios que se sucederam no curso das épocas, acompanhando uma sempre maior urbanização, engrossavam a população da Mouraria de novos indivíduos provenientes das zonas rurais e mais pobres do país. A partir do século $\mathrm{XV}$, enquanto Lisboa se virava para o Tejo, lançando-se com euforia nas descobertas ultramarinas, a Mouraria tornava-se refúgio seguro, nas traseiras da cidade, para aqueles estratos da população mais desfavorecidos e excluídos pelo novo progresso.

10 A partir do século XVIII até meados do XX, a população lisboeta ganha um incremento exponencial, pelo que o bairro da Mouraria atinge a sua capacidade de ocupação e, "decorrente da sua precariedade socioeconómica e funcional, passou a ser entendido com um dos «bairros pobres» da cidade" (Menezes, 2005: 35). Nos últimos trinta anos o território foi atingido por um fenómeno maciço de imigração de indivíduos provenientes da Índia, China e alguns países da África luso e francófona, os quais estabeleceram ali o núcleo das suas relações económicas e sociais.

11 Hoje em dia, a Mouraria caracteriza-se por constituir um bairro densamente povoado, por uma população heterogénea em termos socioeconómicos e culturais. Mas a estigmatização e a segregação (tão simbólica quanto social) que marcam o bairro ainda passam por conceitos ligados à "alteridade", à "pobreza" e à "falta de segurança". Pois a precariedade socioeconómica do seu contexto tem contribuído para o aparecimento de fenómenos ligados à venda e ao consumo de droga e a atividades ilícitas ligadas ao mercado do sexo. No entanto o seu cenário urbano revela-se como um dos mais multiétnicos e culturalmente diversificados que existem hoje em dia na cidade de Lisboa.

12 O seu estar "de costas viradas" relativo aos outros lugares da cidade, o seu ser "terra de conquista de povoações estrangeiras" - antes os mouros, do qual vem o nome, e, no curso das épocas, as populações migrantes- leva-nos a considerar a Mouraria como um território fortemente construído a nível social e espacial face a uma condição de segregação.

13 O conceito de segregação pode bem associar-se ao contexto do bairro se consideramos dois elementos fundamentais. Por um lado, a segregação como um fenómeno espacial. Neste sentido, a identificação da Mouraria como lugar traseiro da cidade e o seu particular desenvolvimento urbano remetem para a ideia de que as figuras históricas 
que representaram o poder e a sua ideologia se inscreveram no espaço, promovendo diferentes valores e manipulando o imaginário socioespacial do bairro (Healey, 2000).

Por outro, a segregação como fruto de algum tipo de guetização social. De acordo com Van Kempen, o conceito de segregação implica, de facto, uma concentração territorial (Van Kempen \& Őzuekren, 1998) que, no caso da Mouraria, nasceu de um espaço delimitado e instituído para o estabelecimento de determinados grupos sociais, económicos e até culturais. $O$ próprio conceito de segregação urbana remete para a ideia de uma separação de determinados grupos sociais no território da cidade, como reflexo ou manifestação das relações que se estabelecem a partir da estrutura social e das suas estratificações (Machado, 2009). Uma estratificação social que, no caso da Mouraria, se expressou - e se expressa - não só através da diversidade socioeconómica, mas também através da exclusão no âmbito do pleno desenvolvimento e acessibilidade aos recursos presentes nas melhores zonas da cidade.

Contudo, a condição histórica e social do bairro contribuiu também para promover algumas formas peculiares de expressão artística, que lá se desenvolveram predominantemente. $\mathrm{O}$ Fado, a maior e mais representativa entre todas, encarna toda a poética de uma classe pobre e excluída às mergens da sociedade (Brito, 1999). Junto com o Fado nasceu, algures no século XIX, a criação de uma tradição popular, ligada ao povo e à realidade social do lugar, que introduzia símbolos e representações que reificavam um denso e articulado imaginário coletivo (Menezes, 2004).

Durante a época do Estado Novo, estas representações foram apropriadas, usadas e ampliadas pelo governo com o intuito de reforçar o sentido de nação, tendo algumas das produções artísticas originárias da Mouraria sido institucionalizadas. A tradição popular converteu-se num veículo de valores e símbolos representativos de uma cultura (Costa, 1999). Nasceram as Festas Populares, através das quais esta tradição é expressa e reproduzida. O processo de "institucionalização" da cultura popular leva consequentemente à instituição das Marchas Populares, em que através da competição e o encontro/confronto entre os diferentes bairros se constrói e fortalece um discurso identitário. Identidade, cultura e tradição que permanecem hoje em dia e se revivificam no período de junho, quando a cada ano se repetem as celebrações dos Santos Populares e o seu poder tipificador revive nos arraiais, nas marchas e nos cantos da tradição (Cordeiro, 1997).

Este imaginário continua a ser produzido e reproduzido quer num contexto interno ao bairro quer nas representações que a cidade faz deste. As suas tradições e representações, social e historicamente construídas, continuam a ser renovadas e promovidas pelas instituições e pelas entidades às quais é atribuída a tarefa de a governar, controlar e valorizar.

\section{A estrutura da reforma e os seus planos}

Entre o outono de 2011 e o verão de 2012, o território da Mouraria e os seus arredores no centro de Lisboa foram objeto de um complexo projeto de reforma sócio-urbanística com vista a modificar o aspeto espacial, social e económico do território. Tal iniciativa foi suportada e dirigida pela Câmara Municipal de Lisboa e por uma série de parceiros, entre os quais um notável número de associações empenhadas no contexto local em atividades de âmbito social. A reforma foi implementada a partir de dois planos de 
intervenção complementares: o Plano de Acção da Mouraria e o Plano de Desenvolvimento Comunitário da Mouraria.

O Plano de Acção da Mouraria (PA Mouraria) constitui um programa de requalificação urbana decorrido de um empréstimo da União Europeia e integrado num Quadro de Referência Estratégico Nacional (QREN), a partir do qual as administrações locais e nacionais tiveram a oportunidade de desenvolver projetos no âmbito da "aplicação da política comunitária de coesão económica e social em Portugal, no período 2007-2013" (in site da CML). Tal plano teve como referente principal a Câmara Municipal de Lisboa (beneficiário do empréstimo e ao mesmo tempo financiador de uma outra relevante quantia de dinheiro) ${ }^{1}$, mas também se articulou num sistema de cooperação entre entidades de parceira, públicas e privadas, que teve como propósito encontrar recursos diferentes para garantir a "intervenção no edificado, no espaço público, no ambiente urbano, nas actividades económicas e nos sectores turístico e cultural" (in site da CML).

O segundo plano, definido como PDCM (Plano de Desenvolvimento Comunitário da Mouraria), nasce a partir de reuniões informais entre algumas associações e coletividades da zona, interessadas (e em parte preocupadas) com o ambicioso projeto de reforma que se estava a desenvolver no território. Tal plano pretendeu complementar os objetivos definidos pela Câmara Municipal com uma série de intervenções de carácter social dirigidas para a população local e baseadas em práticas políticas e princípios de cariz participativo. A ideia do PDCM parte do princípio de "que a liberdade e a cidadania plena só se atingem com o desenvolvimento integral dos indivíduos e das comunidades e que o desenvolvimento político, económico, social e cultural tem, no combate à exclusão social e na promoção da qualidade de vida, a sua prioridade" (Relatório Final PDCM 2011). Deste princípio nasceu a ideia de desenvolver um plano que assistisse e reforçasse as obras de reabilitação urbana com projetos e respostas que se focassem na melhoria de vida dos moradores e tentassem acabar com alguns problemas de estigmatização social do bairro. Embora este tivesse surgido de um modo informal e não institucional, ao longo das suas fases de constituição o PDCM assistiu ao envolvimento de mais de trinta entidades associativas e foi integrado no GABIP $^{2}$ (Gabinete de Apoio ao Bairro de Intervenção Prioritária da Mouraria), financiado e gerido pela Câmara Municipal, acabando assim por participar da estrutura oficial do projeto de reforma urbanística.

\section{As estratégias de intervenção}

21 Como afirmam Fortuna e Leite, as formas e os métodos através dos quais se concretizam as diferentes tipologias de intervenção no contexto urbano apontam para uma profunda ação sobre o território desenvolvida em níveis diferentes e contextuais (Fortuna e Leite, 2009). Da mesma maneira, a reforma sócio-urbanística da Mouraria caracterizou-se por um processo diversificado e articulado que abrangeu diferentes perspetivas de intervenção. Neste artigo analisaremos os quatro eixos de intervenção que, segundo este estudo, constituíram a tentativa de condicionar um tipo de mudança social, económica e representativa do bairro da Mouraria.

(Re)definição das fronteiras. Ao desenvolver uma análise que tome como contexto de estudo um "bairro popular" (tal como vem sendo considerado o bairro da Mouraria), é importante ter em conta aquelas peculiaridades sociais, espaciais, físicas e simbólicas que identificam esses núcleos urbanos face a um sistema de representações endógena e 
exogenamente definido (Cordeiro, 1997). Pela sua natureza histórica, relacional e simbó lica, esses núcleos urbanos constituem unidades temáticas (Lynch in Cordeiro e Costa, 1999) socioespacialmente codificadas e circunscritas dentro do território da cidade.

Além disso, a projetação e implementação de um plano de reforma urbana baseia-se na necessidade de individuar uma unidade territorial funcional ao consentimento dos seus objetivos. Tendo em conta estas reflexões, através da análise dos dois planos (PA Mouraria e PDCM), constatou-se que o interesse demonstrado pela obra de reforma envolveu um território muito mais vasto do que aquele que definiu em termos socioespaciais a Mouraria até hoje em dia. A reforma expande exponencialmente os limites do bairro, abrangendo novas zonas ao seu arredor. Em particular, os focos das intervenções dilataram o território num eixo sul-norte que englobou freguesias como a de São Cristóvão (posicionada entre a Baixa Pombalina e o Castelo) e os arredores do Largo do Intendente (pertencente à freguesia dos Anjos), que se diferenciam do território do bairro, seja por composição socioeconómica do estrato populacional, seja pelas diferentes construções representativas e identitárias assumidas pelos próprios habitantes. Na sua vertente vertical, no entanto, a obra de reforma focaliza o seu centro na Praça do Martim Moniz, desenvolvendo-se em linha reta para englobar aquele conjunto residencial situado nas encostas das colinas, que sobem por um lado até ao Castelo de São Jorge e por outro ao Miradouro da Graça. O território aparece assim claramente situado no meio de três focos fundamentais na identificação de um lugar estratégico no centro de Lisboa.

A decisão de intervir numa zona mais vasta prende-se com o posicionamento geográfico do bairro e remete para uma estratégia de concetualizar um território amplo e integrado no centro de Lisboa, acessível e de conexão para outros pontos da cidade: um lugar de ligação entre vários eixos económicos e culturais, ou seja, um lugar inserido numa rede de lugares. Este tipo de redefinição territorial traz consigo importantes significados simbólicos e socioespaciais. Pois entende quebrar as barreiras físicas e simbólicas que antes "confinavam" a Mouraria e lhe atribuíam o estigma de bairro fechado, retraído e pouco inclinado ao "aproveitamento" do setor turístico e imobiliário; este, pelo contrário, renova a introdução de uma ação exógena e quer favorecer novos modelos de apropriação de recursos materiais (equipamentos, infraestruturas, serviços públicos) e imateriais (património cultural) que o bairro tem. Ao mesmo tempo, a dilatação das fronteiras expande um "universo simbólicorepresentativo" sobre outros territórios, tentando atribuir-lhes novos discursos identitários enquanto se constroem novas representações do lugar.

Práticas securitárias. Um bairro caracterizado como um lugar de segregação, território turvo e arriscado, rede labiríntica de entradas seguras mas de saídas incertas, não pode utilizar outra forma, para voltar a "apresentar-se à cidade", senão a de resgatar as esquinas, becos e largos da sua malha urbana, longamente esquecidos pela intervenção pública. $\mathrm{Na}$ articulada obra de reforma sócio-urbanística, a intervenção sobre o espaço público assumiu uma importância central, enquanto foi entendida como "indutora de novos comportamentos" (CML, Boletim Oficial).

Segundo o PA Mouraria, a intervenção sobre o espaço público devia consistir em dois momentos sequenciais em relação de causalidade. Por um lado, o plano foi utilizado para intervir na rede urbana do bairro de forma a promover uma acessibilidade diferente e mobilidade dentro e em redor do seu território (manutenção das ruas, regulação do trânsito, ilhas pedonais, praças renovadas e espaços de lazer). Por outro, 
esta reabilitação física devia contribuir, segundo as instituições, para estimular novas formas de uso e aproveitamento do espaço: a acessibilidade ao bairro e uma maior liberdade de movimentação dentro do seu território; mas também uma "regulamentação" em forma de disciplina que seria constituída para promover novas práticas comportamentais no meio ambiente urbano, reduzindo fenómenos considerados de "mau costume" (lixo na rua, estacionamento nas passadeiras), muitas vezes induzidos pela falta de regulamentação ou equipamentos.

27 A estes tipos de iniciativas (de carácter «regulador» e, em parte, «higienista») que vinham implementadas na conceção do PA Mouraria, acrescenta-se ainda a vontade de estimular a "afluência" de novos indivíduos sociais ao território do bairro e contrastar (quando não impedir) práticas ilegais (tráfico e consumo de droga «ao ar livre», mas também fenómenos de prostituição), que estavam a minar a sensação de segurança nos indivíduos que transitavam pelo bairro e contribuíam ainda para a forte estigmatização deste.

28 A este respeito o discurso da segurança representou um tema fundamental nos objetivos expressados nos dois planos de reforma. As associações parceiras do PDCM, por exemplo, aportaram um sério contributo à consideração do carácter social da segurança no espaço público. Para enfrentar os vários pedidos de segurança provenientes de alguns moradores e retomados pelas instituições (os quais suporiam uma intervenção mais repressiva dos fenómenos de ilegalidade), as associações do bairro pressionaram para que tais fenómenos não fossem tratados a partir de uma atitude repressiva mas, pelo contrário, como fenómenos aos quais era preciso contrapor políticas de prevenção e assistência. Com este intuito elas propuseram devolver dois espaços (daqueles recentemente reestruturados e equipados nas intervenções) a lugares de assistência e prevenção para as toxicodependências, onde os consumidores poderiam consumir em regime de controlo e segurança para eles próprios. Uma conceção de segurança, segundo o PDCM (definida como perspetiva de segurança), que se expressa como fruto da prevenção dos fenómenos de risco e assenta, de maneira crítica e participada, no uso coletivo do espaço público.

29 A reforma do espaço público não passou entãosópela requalificação da malha urbana mas também por formas de gestão e apropriação social do seu meio ambiente. Conceitos como "práticas cívicas" (indicadas pelo PA Mouraria) ou "uso colectivo do espaço" (referida pelo PDCM) reforçam a ideia de que, na obra de reforma, o espaço público é entendido como uma realidade produzida e produtora de dinâmicas sociais.

30 Além disso, na visão dos planos o fenómeno espacial assume um significado decisivo dentro da mesma construção do conceito de «comunidade». Um espaço mais seguro, novos modelos de comportamento cívico e renovadas práticas de sociabilidade no contexto urbano qualificam-se como os catalisadores sociais e os referentes identitários do auspiciado desenvolvimento comunitário.

31 A revitalização económica. Do ponto de vista das repercussões socioeconómicas que a reforma entendeu induzir, o PA Mouraria e o PDCM abordaram através de modelos e perspetivas diferentes o conceito de revitalização económica e as consequências que esta podia comportar nas componentes sociais do bairro.

32 Nos objetivos do PA Mouraria, a reabilitação socioespacial do território era dirigida para o advento de novos e diferentes grupos sociais que complementassem o substrato residente originário, na participação e na promoção socioeconómica do território. Tal participação não era restringida só para um renovado fluxo turístico que aproveitasse 
as ofertas culturais promovidas no território, mas era aberta também ao estabelecimento de novos estratos de população que entrassem em níveis diferentes no tecido económico e social local. Por exemplo, parte dos esforços foram dirigidos à reabilitação de prédios e focos que hospedassem estudantes (sobretudo estrangeiros) e novos residentes. Mas era também entendida como impulso dirigido aos investimentos privados na abertura de novas atividades comerciais (lojas, bares, restaurantes) com um mercado-alvo diferente. Basicamente as intenções da Câmara Municipal assentaram na ideia de complementar a população originária com novas classes socioeconómicas extralocais, de acordo com uma dinâmica gentrificadora.

Pelo contrário, as associações parceiras do PDCM empenhadas no território expressaram a necessidade de intervir no potenciamento da condição socioeconómica da população residente. De acordo com o modelo proposto pelo PDCM, esta conceção concretizava-se através da criação de novas formas de emprego e na formação e capacitação do substrato populacional originário. Tais iniciativas ocorreram assim através da criação de cursos de formação, abertura de fundos de empréstimos ad hoc, criação de cooperativas de trabalho, estabelecimento de novas formas de contratos sociais e económicos entre os residentes e as instituições locais. Ao mesmo tempo, quisse atuar no potenciamento das formas de inclusão social: criação de novos grupos associativos, intensificação da obra de assistência e apoio às pessoas necessitadas e aumento da oferta de bens e serviços abertos a toda a população.

Aparece então, na dialética da obra de reforma, o conceito de "balanceamento social" que tende a definir uma estratégia socioeconómica (e política), a qual pretende "balançar o potenciamento dos recursos endógenos, com novos recursos exógenos" (João Menezes, coordenador do GABIP).

Patrimonialização e construção de uma identidade. Outro aspeto no qual a intervenção conjunta dos planos insiste é a questão da patrimonialização e da promoção de uma identidade compartilhada, baseada na reprodução de elementos históricos, sociais e culturais. Este aspeto reconduz à construção sociocultural que se fez da Mouraria nas épocas anteriores. Retomam-se então os mitos e os significados ligados a este nome.

No PA Mouraria, a requalificação do espaço público vem entendida também como forma de revitalização do património local através da requalificação de edifícios de valor simbólico e patrimonial para o bairro. A criação de percursos e rotas turísticoculturais, a reestruturação da antiga Cerca Moura, a edificação de uma Casa de Fado no centro do bairro são expressões desta intenção de revitalização patrimonial. A requalificação do espaço coincide com aquela imagem urbana do bairro e volta a apoiar-se sobre a idealização de determinadas tradições baseadas num passado pensado como histórico. Retomam-se então discursos referidos à tradição popular, àquela ideia de "genuinidade" e "autenticidade folclórica" própria de uma determinada história social do bairro. A esta junta-se a construção, que surgiu nas ultimas décadas, de uma Mouraria símbolo do convívio "multiétnico" e/ou "multicultural", que se quer ligar de maneira "coerente" (também demagógica) ao seu mito de fundação e à origem mourisca. Discursos que, com o apoio de importantes eventos culturais promovidos no território, contribuem para a quebra da estigmatização ligada à "alteridade" que longamente caracterizou esse bairro.

37 Mas a criação de uma identidade sociocultural vai para além de uma política de patrimonialização. A ideia de identidade expressa pelos planos parece acompanhar-se de uma ideia de construção de uma comunidade sociocultural. Isto revela-se em 
particular nas iniciativas sociais que os planos desenvolvem. Através das associações parceiras do PDCM desenvolvem-se numerosas iniciativas destinadas à produção de sociabilidade: realização de trabalhos de grupo, criação de coletividades, laboratórios de solidariedades intergeracional e intercâmbio cultural, mas também produções artísticas baseadas na realidade local. A este respeito, o elemento participativo foi utilizado mais uma vez para desenvolver reflexões sobre o uso coletivo dos recursos, da pluralidade: então, sobre uma certa ideia de comunidade.

A obra dos planos envolveu-se, assim, de um forte significado representativo. 0 passado tradicional, tipificado em práticas, símbolos e significados socioespaciais, foi acompanhado pela construção de novos sentidos "histórico-culturais", tentando criar um padrão coerente na produção de imagens e conceitos próprios de uma narrativa identitária.

\section{Abertura}

39 A problemática que este artigo trata sai de uma pergunta inicial: "Como as políticas urbanas agem sobre a mudança social e as representações de um bairro?” Tentamos neste ponto interpretar os dados recolhidos para tentar individualizar as diretrizes das intervenções no intuito de refletir sobre uma possível "hermenêutica da reforma". A análise dos planos, as entrevistas feitas aos seus responsáveis, os encontros informais e as conversas com os representantes das associações permitiram identificar um conceito que estruturou as intervenções e definiu a ideia inspiradora da obra de reforma sóciourbanística na Mouraria. Este corresponde ao conceito de abertura. O conceito de abertura representa um ponto extremamente importante no enquadramento do sistema de intervenção que estamos a analisar, visto que permite perceber as estratégias desenvolvidas e ler os possíveis significados a elas atribuídos.

De maneira física ou conceitual, a abertura da Mouraria vem entendida como a possibilidade de aceder ao bairro, poder entrar e sair dele, atravessá-lo de uma ponta a outra, torná-lo um território de passagem, de transitoriedade, de confluência - quer de pessoas quer de mercadorias -, na prática, segundo uma certa ideia, reterritorializá-lo. Mas esta obra de abertura pode ser entendida também como a descaracterização do bairro, pois, ao redefinir os seus contornos e diversificar o seu tecido social, a abertura pretende recusar a estigmatização socioespacial pela qual é conhecido. No entanto, ela não pressupõe minar as construções e as representações que o caracterizam na relação identitária que tem com a cidade.

41 O conceito de abertura nasce de uma análise etnográfica e a assunção de tal deriva das entrevistas e dos diálogos com os interlocutores, enquanto o conceito surgiu da análise dos planos. Porém, o trabalho de campo demonstrou como este conceito - partilhado a nível teórico e conceitual - é construído, utilizado e elaborado de maneiras diferentes, às vezes até antitéticas, entre todas as entidades envolvidas no processo de mudança do bairro.

42 Na visão do PA Mouraria (o plano das instituições), a abertura é percebida como a melhoria dos percursos e dos eixos de entrada, saída e atravessamento do bairro, de molde a constituir uma maior acessibilidade e mobilidade dentro e em redor dele. Tal intervenção no espaço público é suportada também por uma reabilitação física do território, com a criação de novos prédios e equipamentos, que quer contribuir para reabilitar a imagem urbana do bairro atraindo um novo tipo de capital social. Esta ideia 
de abertura assenta também no propósito de criar os pressupostos para o estabelecimento no bairro de novas classes sociais, com uma melhor condição socioeconómica e diferentes interesses culturais. O processo que foi definido como "balanceamento social" refere-se ao envolvimento de novos grupos sociais no contexto socioespacial do território, na esperança de que eles tragam novos e diferentes investimentos, recursos, iniciativas económicas e que deem um maior impulso ao desenvolvimento socioeconómico e cultural do bairro. Assim, na visão do PA Mouraria, a abertura do bairro a novos espaços - sociais, culturais e económicos - coincide com a abertura a novos indivíduos - sociais, culturais e económicos.

De maneira contrária, na ideia do PDCM (plano das associações), o conceito de abertura é entendido a partir de uma visão endógena do real benefício que pode trazer à população a obra de reforma, em termos de possibilidade para uma maior emancipação e integração dentro da cidade. Abertura neste caso significa criar equipamentos para a formação, a capacitação e o emprego dos desocupados; disponibilizar recursos para ajudar as pequenas empresas ou realidades económicas locais; criar redes associativas comunitária. Em particular a ideia de abertura proposta pelo PDCM apoia-se no fator fundamental do envolvimento e participação da população residente na gestão e nas estruturas de organização do bairro. Um envolvimento que interessa a população em múltiplos aspetos e que, em consequência, a torna responsável em questões de apropriação, salvaguarda e produção dos recursos internos, nomeadamente através do uso social do espaço público. Além disso, a participação e o envolvimento da população como objeto de uma reforma social do bairro desenvolve-se através de linhas e temáticas "poliédricas" que muitas das vezes desembocam num variado conjunto de projetos artísticos e culturais. A participação coincide com a assunção das problemáticas e das questões remetidas pelos indivíduos a partir da própria vida quotidiana, o que significa então fazer voltar o plano de reforma de um contexto exógeno e histórico para um endógeno e quotidiano, já que muitos destes projetos tentam revelar e reatualizar a dimensão subjetiva como fator socialmente fundamental na definição de um bairro e das suas problemáticas.

O conceito de abertura remete então para a conceção política e social de dar vida a um processo de reforma sócio-urbanística que aborde de alguma maneira as questões de segregação socioespacial ainda presentes na Mouraria, lute contra a estigmatização que a caracteriza e crie os pressupostos para um processo de "incorporação" do bairro na cidade. No entanto este foi entendido de maneira diferente. As instituições consideraram a abertura um processo de incorporação do bairro na cidade através da entrada da Mouraria nas rotas turísticas urbanas e do envolvimento de novos estratos da população externos à realidade do bairro, desenvolvendo assim uma dinâmica "defora para-dentro". Ao contrário, a visão expressa pelas associações que tomaram parte no projeto de reforma identificou o conceito de abertura como um processo de emancipação da população e de fornecimento de novos equipamentos para a resolução das problemáticas dinâmicas sociais que estigmatizam o bairro no contexto urbano, tentando desenvolver assim uma dinâmica "de-dentro para-fora".

Em tudo isto cabe a construção de uma renovada imagem do bairro que parte das antigas construções socioespaciais e representativas da Mouraria como bairro segregado, pobre e perigoso. 


\section{Considerações finais: as incógnitas sobre o futuro do bairro}

Contudo, apesar das expectativas de um desenvolvimento sensível e participado, esta reforma na Mouraria impõe-se como uma obra implementada a partir do exterior, expressão de uma clara linha política que revela uma estratégia socioeconómica para o desenvolvimento do centro de Lisboa.

Na medida em que as instituições (a Câmara Municipal e as entidades públicas competentes) procuraram encontrar ligações e concertar referentes endógenos para mediar as suas intervenções no território, estas não se revelaram competentes para submeter, na avaliação dos planos, a adequada complexidade do contexto socioeconómico e cultural que articula o bairro. Isto porque, embora se recorresse ao apoio e à parceria de numerosas associações que operavam no território, a maioria destas não eram compostas (nem muitas vezes interagiam a nível da confiança e da reciprocidade) pela população originária do bairro. Isto levou a que não fosse possível representar de maneira adequada os pontos de vista endógenos.

Por exemplo, os moradores portugueses da Mouraria, estabelecidos na sua maioria no antigo centro do bairro (aquele conjunto de ruas e pracinhas da freguesia do Socorro que são consideradas o "berço do Fado"), tiveram sempre uma grande reticência (às vezes uma efetiva aversão) em relação ao trabalho da associação Renovar a Mouraria, cooperativa que desenvolve iniciativas e ações sobre a legalidade e a interculturalidade no bairro, e foi escolhida pela Câmara Municipal como referente principal da obra de reforma no território. Pelo contrário, o único referente identitário deste núcleo de população pareceu ser o Centro Desportivo da Mouraria, sede do único ginásio do bairro e grupo que organiza e prepara as Marchas Populares de Junho (que nunca participou nas reuniões com as instituições ou com o PDCM).

Outro exemplo é aquele relativo ao envolvimento ou à consulta nas fases de projeto de grupos ou associações de imigrados. Na Mouraria vive uma percentagem provavelmente maioritária (difícil conseguir percentuais atendíveis) de pessoas imigradas. Mesmo assim, no bairro não existem grupos ou associações oficiais que tutelem ou representem instâncias referidas à pertença sociocultural. Existem, muito embora, duas mesquitas que agrupam um consistente número de fiéis muçulmanos, pertencentes a diferentes grupos socioculturais. A obra de reforma da Mouraria, através das entidades que a implementavam, nunca chegou a um envolvimento de facto destes grupos e de todas as realidades mais ou menos informais, mas fundamentais para considerar em pleno a complexidade de problemáticas que ocorrem no bairro.

Além disso, como afirmado acima, a vastidão das intervenções cobre um território extremamente diversificado, seja pela composição socioeconómica dos estratos de população que residem nas diferentes zonas, seja pela definição identitária dos seus moradores. Estas deixam de ter em conta as variáveis sociais existentes no território, como as construções valorativas e simbólicas que definem o bairro pelos indivíduos e pelos grupos sociais que lá moram. A Mouraria definida por esta reforma é um território recriado, que forja a sua imagem em discursos reinventados sobre uma profunda renovação do contexto social anterior.

51 Para concluir, esta obra de reforma sócio-urbanísticanão deixa dúvidas sobreos reais processos de mudança que pode comportar num complexo contexto social como é o da 
Mouraria. Referindo-nos em particular aos quatro eixos de atuação que inspiraram a reforma, cabe aqui perguntar-nos: poderá a modificação do espaço público limitar, contrastar, alterar práticas precedentemente definidas como ilegais ou de exclusão social, que anteriormente se desenvolviam nas ruas e nas praças do bairro? Que tipo de dinâmicas produzirá a entrada maciça no contexto social do bairro de novos indivíduos e grupos sociais, atraídos por novas possibilidades de "exploração" e portadores de diferentes práticas de apropriação do espaço? Neste sentido, como será gerida a implementação de novos equipamentos? Será garantida a acessibilidade dos diferentes grupos sociais presentes no território? Estamos perante uma explícita tentativa de gentrificação? E, finalmente: será possível criar uma identidade comunitária que tenha como referente esta nova entidade territorial? Tentar-se-á alcançar este processo através de políticas multiculturalistas genéricas e da construção de artificiais tradições e discursos identitários, ou haverá um verdadeiro interesse em valorizar e expressar as diferenças presentes nos diversos grupos socioculturais que povoam este bairro?

Todas estas questões remetem para um futuro mais próximo, no qual o bairro da Mouraria inscreverá uma outra etapa da sua longa e particular história. Com esta obra de reforma, a Mouraria reafirma mais uma vez a importância que tem no cenário político e social do contexto urbano lisboeta e renova, como sempre fez no passado, a profunda ligação que une a sua história à da cidade de Lisboa.

\section{BIBLIOGRAFIA}

BRITO, J. P. (1999), “O fado: etnografia na cidade”, in G. Velho, Antropologia Urbana: Cultura e Sociedade no Brasil e em Portugal, Rio de Janeiro, Jorge Zahar Editor.

CÂMARA MUNICIPAL de LISBOA (2011), A Mouraria vai mudar para melhor - Boletim Oficial Plano de Reabilitação Urbana, setembro 2011, Lisboa.

CÂMARA MUNICIPAL de LISBOA (2011), Plano de Desenvolvimento Comunitário da Mouraria Relatório Final, abril 2011, Lisboa.

CORDEIRO, G. Í. (1997), Um lugar na cidade: Quotidiano, Memória e Representacão no Bairro da Bica, Lisboa, Publicações Dom Quixote.

CORDEIRO, G. Í. e F. da Costa (1999), "Bairros: contextos e intersecção", in G. Velho, Antropologia Urbana: Cultura e Sociedade no Brasil e em Portugal, Rio de Janeiro, Jorge Zahar Editor.

COSTA, F. da (1999), Sociedade de Bairro, Oeiras, Celta Editora.

FORTUNA, C. e R. P. Leite (orgs.) (2009), Plural de cidade: Novos Léxicos urbanos, Coimbra, AlmedinaCES.

GALSTER, G. (2001), On the nature of neighborhood, Urban Studies, vol. 38.

HANNERZ, U. (1980), Exploring the city. Inquiries Toward an Urban Anthropology, Columbia University Press. 
HEALEY P. (2000), "Institutionalist theory, social exclusion and governance", in J. Madanipour et al., Social Exclusion in European cities, Londres, Routledge.

LEDRUT, R. (1978), “Quartiere e articolazioni minori nella citta”, in P. Guidicini, Gruppi e subunità spaziali nella città. Quartiere, vicinato e area naturale tra miti utopie e valutazioni critiche, Roma, Città Nuova.

MACHADO, L. M. (2009), “Segregações urbanas”, in Fortuna \& Leite, Plural de cidade: Novos Léxicos urbanos, Coimbra, Almedina-CES, pp. 115-126.

MENEZES, M. (2004), Mouraria, retalhos de um imaginário, Oeiras, Celta Editora.

MENEZES, M. (2005), “Património Urbano: por onde passa a sua salvaguarda e reabilitação?”, em “Cidades: comunidades e territórios”, CET n. 11, pp. 67-83.

MENEZES, M. (2012), “Debatendo mitos, representações e convicções acerca da invenção de um bairro lisboeta", Sociologia, Revista da Faculdade de Letras da Universidade do Porto. Número temático Imigração, Diversidade e Convivência Cultural, pp. 69-95.

PAQUOT, T. (2009), L'espace public, Paris, La Découverte.

SAVAGE, M. et al. (2005), Globalization and belonging, Londres, Sage.

SMITH, N. (2002), “New Globalism, New Urbanism: Gentrification as Global Urban Strategy”, in Antipode, vol. 34 .

VAN KEMPEN, R. e A. S. Őzuekren (1998), On the social significance of segregation, European Research Centre on Migration and Ethnic Relations, PhD Research, University of Bristol.

Sites consultados

http://www.aimouraria.cm-lisboa.pt [consultado entre outubro 2011-março 2012].

\section{NOTAS}

1. Segundo os dados fornecidos pelo site oficial da obra de reforma, a União Europeia, através do programa QREN, destinou sete milhões de euros à implementação das intervenções de reforma. A estes juntaram-se os cinco milhões de euros estabelecidos pela Câmara Municipal de Lisboa como promotora do projeto (http://www.aimouraria.cm-lisboa.pt).

2. 0 Gabinete de Apoio ao Bairro de Intervenção Prioritária da Mouraria (GABIP) é uma entidade que foi constituída no final do 2010 para coordenar as diferentes entidades que participaram na obra de reforma. Esta estrutura, além de operar como mediadora entre as várias propostas de ação expressas pelos parceiros, destaca-se como entidade oficial de representação da obra de reforma e posiciona-se como referente principal no diálogo com outras entidades públicas, privadas ou com os moradores.

3. A ambiguidade e a grande genericidade deste termo constringe-nos a definir melhor a sua entidade e as suas significações. Infelizmente não há fontes oficiais que possam legitimar tal tarefa. O substantivo "balanceamento" deriva de uma palavra de origem luso-brasileira, enquanto a locução "balanceamento social" não aparece em nenhum dicionário ou revista especializada do setor. Tal expressão é então referida assim como adquirida pelos discursos dos operadores e dos indivíduos que tomaram parte no processo de planeamento e implementação da obra de reforma. Mais propriamente, este termo surgiu pela primeira vez num discurso do coordenador do GABIP, João Menezes, que "se atribuiu a tarefa" de o definir nas suas especificidades e significações. 


\section{RESUMOS}

O bairro da Mouraria sempre se caracterizou por ser um território socioespacialmente segregado. Neste lugar, história e tradição conviveram ao longo das épocas num cenário de pobreza e de estigmatização induzida e autorreproduzida. No começo da segunda década do século XXI, um complexo projeto promovido pelas instituições e as associações locais tenta mudar o destino e as representações sobre esse território.

O presente artigo desenvolve uma análise do plano de reforma sócio-urbanística que ocorreu na Mouraria; estuda as estratégias e as práticas de intervenção e tenta descodificar os significados que lhes são atribuídos. Ao mesmo tempo, o trabalho levanta questões sobre o tipo de desenvolvimento social, económico e cultural que se quer induzir no bairro: expressão de uma específica política urbana para a cidade de Lisboa.

The neighborhood of Mouraria has always been characterized as a socio-spatially segregated territory. In this area, history and tradition cohabited in the course of time in a setting of poverty and stigmatization both induced and self-reproduced. At the beginning of the second decade of the XXI century, an important plan of the local institutions and various associations tries to change the fates and representations of this territory.

This article provides an analysis of the plan for urban social reform that involved the neighborhood of Mouraria; it studies the strategies and practices of the intervention, and attempts to decode the meanings assigned to them. In the meanwhile, this work questions the kind of social, economical and cultural development it intends to induce in the neighborhood: as an expression of a specific program of urban politics in the city of Lisbon.

\section{ÍNDICE}

Keywords: Neighborhood, Mouraria, urban social reform, opening

Palavras-chave: Bairro, Mouraria, reforma sócio-urbanística, abertura

\section{AUTOR}

\section{GIACOMO FERRO}

Mestrado em Antropologia Aplicada FCSH-UNL, doutorando em Estudos Urbanos - FCSH-UNL/

ISCTE-IUL (giacomoferro.gf@gmail.com) 